\title{
Determination of the proportion of refractive errors in patients with primary complaint of headache and the significance of refractive error correction in symptoms relief
}

\author{
Srimathy A Jain ${ }^{1}$, Sutapa Das ${ }^{2, *}$, M. Subashini ${ }^{3}$, Kaviraj Mahadevan ${ }^{4}$ \\ ${ }^{1}$ Post Graduate, ${ }^{2}$ Associate Professor, ${ }^{3}$ Professor and Head, ${ }^{4}$ Research Associate, Dept. of Ophthalmology, Sri Manakula \\ Vinayagar Medical College and Hospital, Puducherry, India
}

*Corresponding Author:

Email: sdasavmc@gmail.com

\begin{abstract}
Introduction: Headache attributed to refractive errors (HARE) is a common condition caused by myopia, hypermetropia, and astigmatisms. Headache is not necessarily experienced by all individuals with REs. HARE is mainly caused by the strain produced in the ciliary muscles to focus objects more often during near works like reading. This study is an attempt to estimate REs with headache and symptoms relief after correction respectively.

Materials and Methods: 103 cases of both sexes with mean age 19.04 \pm 7.27 years referred to the ophthalmology out patient department with complain of haedache were included in the study. Objective refraction was measured with $0.5 \%$ cyclopentolate drops and retinoscopy was done with suitable lenses. All cases were followed up for a period of one month.

Results: The frequency of REs in headache patients was found to be (29) $28.15 \%$ with hypermetropia $9(31.03 \%)$, myopia $6(20.69 \%)$, mixed astigmatism 5(17.24\%), compound myopic astigmatism 4(13.79\%), compound hypermetropic astigmatism $3(10.34 \%)$, simple myopic astigmatism 2(6.90\%). Asthenopia was found in $62 \%$ of cases diagnosed with RE. Symptoms relief was seen in $69 \%$ of cases after spectacles prescription. 16 out of 19 patients with asthenopia experienced symptoms relief after one month.

Conclusion: Among the many causes of headache, HARE is a subgroup to be resolved with ophthalmological consultation. The results of this study indicates a positive association of Res in causing headache and the importance of lens correction in symptoms relief. So, all headache cases should have ophthalmological examination since maximum amount of success is possible in HARE management.
\end{abstract}

Keywords: Asthenopia, Astigmatism, Headache, Hypermetropia, Myopia, Refractive error.

\section{Introduction}

Specific eye diseases, such as acute glaucoma, refractive error, heterophoria and heterotropia, ocular inflammatory disorders such as iritis, uveitis, scleritis and optic neuritis ${ }^{1}$ are often associated with headache which is an important health complaint and disability worldwide ${ }^{2,3}$ Headache is classified into three types, 1 . Primary, 2. Secondary and 3. Painful cranial neuropathies, other facial pains and other headaches by the International Headache Society (IHS). ${ }^{4}$ Primary headaches do not have an underlying disorder. Headache attributed to disorders of the eye are classified under secondary headaches. ${ }^{1}$

Refractive errors (REs) affect a large amount of population worldwide, irrespective of age, sex and ethnic group. These refractive errors when diagnosed are corrected with spectacles or other refractive corrections to attain normal vision. ${ }^{5}$ The exact role played by refractive errors in the etiology of headache is still inconclusive ${ }^{6}$ Literature evidences significant positive association of refractive errors and headache. On the other hand prevalence of headache is considered as coincidental among the population irrespective of REs. $^{7,8}$

Asthenopia is an ocular discomfort leading to headache and pain in eyes with symptoms like eyestrain, easy fatigability after reading, and heaviness of lids after reading. It is caused by uncorrected refractive errors. ${ }^{9}$ Refractive errors that could possibly contribute to headache includes, emmetropia and ammetropia. Emmetropia is defined as the state of refraction wherein the parallel rays of light coming from infinity are focused on the retina, when the accommodation is at rest. The emmetropic eye relies in a relaxed state and focused on an object more than 6 meters or 20 feet away without any effort. Emmetropia is a condition between myopia and hypermetropia in which light rays from the source are too divergent and not focused properly into the retina. Ammetropia is defined as a state of refraction wherein the parallel rays of light from infinity are focused either in front or behind the retina when the accommodation is rest. It includes myopia, hypermetropia, and astigmatism. The strain produced in hypermetropia and astigmatism to focus during near works like reading is more related to headache symptoms. ${ }^{10}$

Diagnostic criteria to confirm that the headache is attributed to refractive error are,

1. Uncorrected or miscorrected refractive error in one or both eyes,

2. Criteria fulfilling at least two of the following:

i. Headache has developed and/or significantly worsened in temporal relation to the onset or worsening of the refractive error.

ii. Headache has significantly improved after correction of the refractive error. 
iii. Headache is aggravated by prolonged visual tasks at an angle or distance at which vision is impaired.

iv. Headache significantly improves when the visual task is discontinued. ${ }^{1,4}$

This study attempts to find out the proportion of refractive errors in patients attending the outpatient department with complaints of headache and improvement in symptoms after spectacle correction.

\section{Materials and Methods}

Study Design: This hospital based cross-sectional study was carried after obtaining approval from the institutional ethics committee in eligible patients who presented to Sri Manakula Vinayagar Medical College and Hospital, Puducherry from September 2013 to January 2015 with headache as a primary complaint for duration of one month or more. The sample size was calculated as 94 with 95\% CI using open Epi Software (version 2.3). Considering $10 \%$ of subjects as nonresponse, the final sample is 103 .

Inclusion Criteria: Patients in the age group of <40 years including male and female cases attending the ophthalmology outpatient department with primary complaint of headache with duration of one month or more, were included in the study.

Exclusion Criteria: Patients who have already been diagnosed with refractive error, patients with other eye diseases like inflammations (iridocyclitis. scleritis), glaucoma, and other diseases that may be attributed for causing headache as described in the IHS (International Headache Society) criteria were not included in the study.Patients with corneal opacities, optic atrophy and other diseases in which subjective improvement cannot be done were also excluded.

A written informed consent was obtained from all patients who were eligible for the study, based on the inclusion criteria. For the patients below 16 years of age, informed written consent was obtained from the parent.
Each patient was then subjected to a complete workup which included a full medical history and a detailed history regarding the nature of the headache - the location of headache, total duration of headache, duration of each episode, frequency, associated symptoms like aura, asthenopia, photophobia, phonophobia, nausea, vomiting, triggering and relieving factors of headache and history regarding diminution of vision were taken.

All patients underwent a complete ocular examination including visual acuity testing, objective refraction and dilated fundus examination. Objective refraction was measured after assessing the visual acuity, by instillation of $0.5 \%$ cyclopentolate drops in the conjunctival cul-de-sac of both the eyes. After 40 minutes retinoscopy was done at 1 meter distance by neutralizing the retinal reflexes using suitable lenses in the two principal meridians. Subjective correction and Post mydriatic test was done after 3 days. Patients with refractive errors were prescribed glasses and followed up after 1 month.

\section{Results}

A total of 103 patients, 53 males and 50 females were enrolled in the study. The age group ranged from 6-36 years with a mean of $19.04 \pm 7.27$ years.

Distribution of refractive errors: Of the 103 patients, $29(28 \%)$ patients were diagnosed with refractive errors. 19 patients of the 103 patients, presented with asthenopic complaints out of which 18 had refractive error while 1 was diagnosed with convergence insufficiency (Table 1). Out of 29 patients with refractive errors, $6(20.69 \%)$ were diagnosed with myopia, $9(31.03 \%)$ with hypermetropia, 2(6.90\%) with simple myopic astigmatism, 4(13.79\%) with compound myopic astigmatism, 3(10.34\%) with compound hypermetropic astigmatism and $5(17.24 \%)$ with mixed astigmatism. None of our patients had simple hypermetropic astigmatism (Fig. 1).

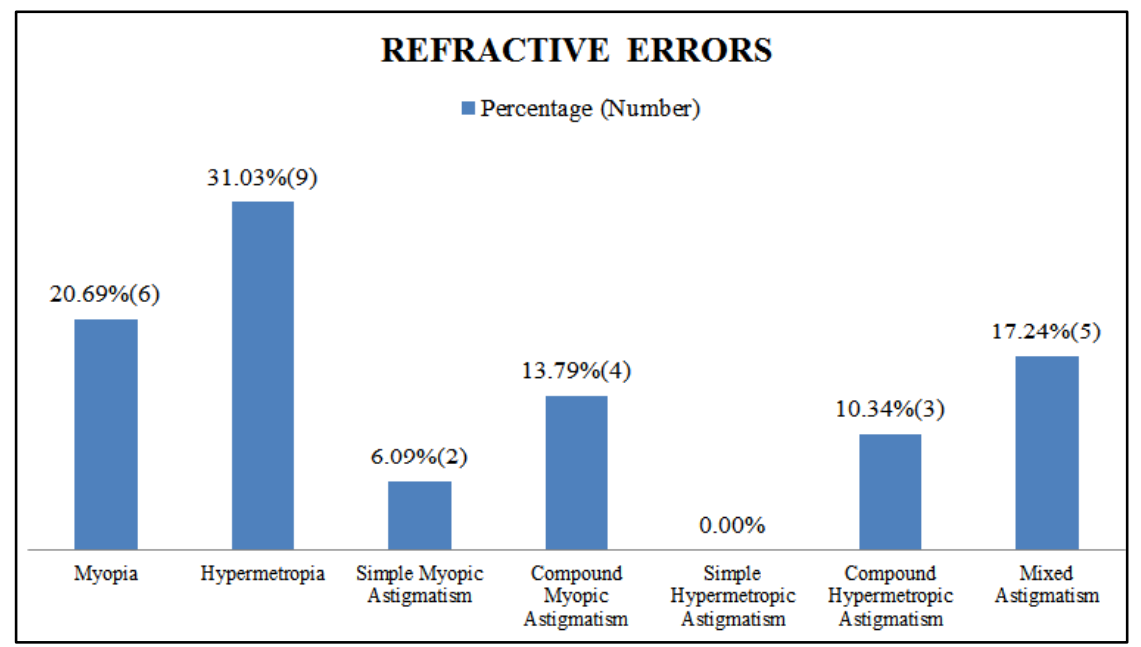

Fig. 1: Distribution of RE among headache cases

Hypermetropia is the most common RE associated with headache followed by myopia. 
In myopic patients, the amount of myopia ranged from $0.50 \mathrm{DS}$ to-3.00 DS with a mean of $-1.50 \pm-1.00 \mathrm{DS}$. Hypermetropia ranged from $+0.50 \mathrm{DS}$ to $+2.25 \mathrm{DS}$ with a mean hypermetropia of $+1.50 \mathrm{DS} \pm+0.75 \mathrm{DS}$. Myopic Astigmatisms ranged from -0.50 to $-1.50 \mathrm{D}$ and hypermetropic astigmatisms ranged from $+0.50 \mathrm{DC}$ to +1.50 DC.

Distribution of refractive errors in asthenopia: Out of 29 patients who had refractive errors, 18 patients
(62\%) had complaits of asthenopia, and 11 patients (38\%) had no complaints of asthenopia. The 19 patients with asthenopiaform $18.44 \%$ of the patients in our study out of which 6 were diagnosed with hypermetropia, 2 with simple myopic astigmatism, 2 with compound myopic astigmatism, 3 with compound hypermetropic astigmatism and 5 with mixed astigmatism (Fig. 2).

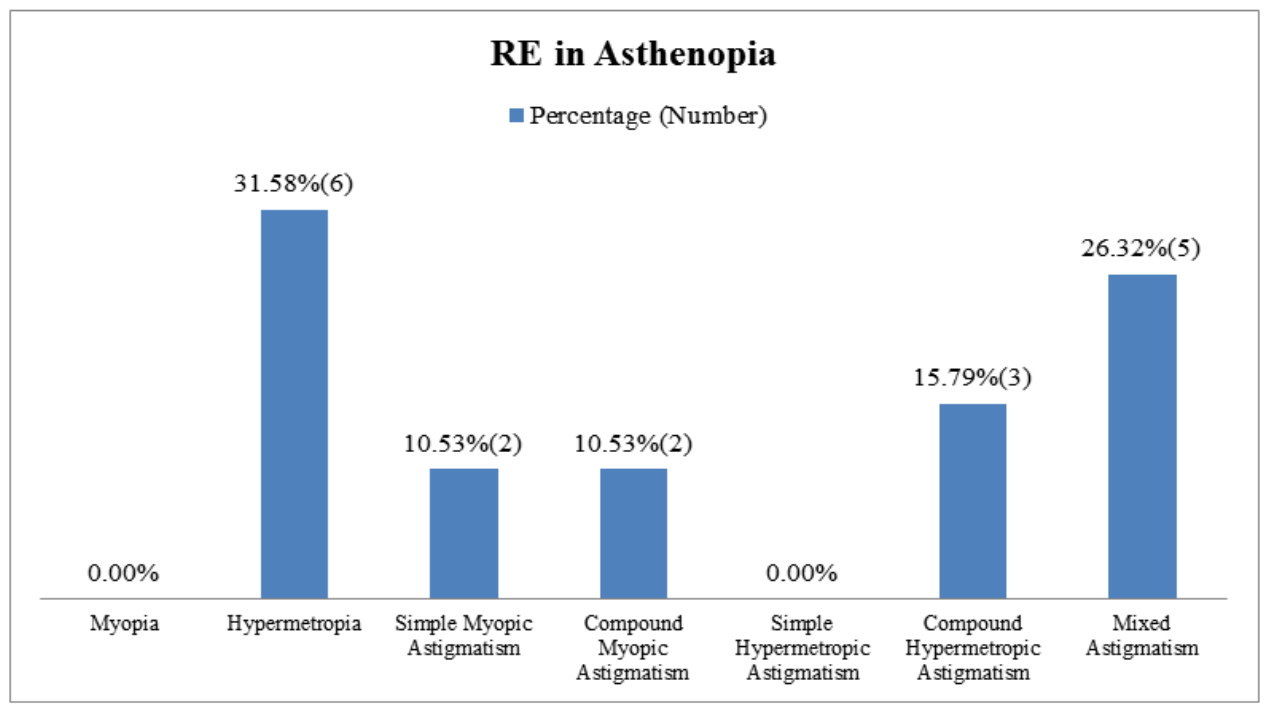

Fig. 2: Distribution of RE among headache cases associated with asthenopia

Hypermetropia is the most common RE found in patients with asthenopic complaints. No incidence of myopia

Symptom relief after RE correction: Out of the 29 patients with refractive errors, 20 patient's symptoms were relieved after refractive error correction by corrective lenses during the follow up at 1 month. 100\% relief was seen in simple myopic astigmatism and compound hypermetropic astigmatism followed by hypermetropia (89\%), mixed astigmatism (80\%) and compound myopic astigmatism $(50 \%)$. One patient (16\%) with myopia experienced relief during the follow up. Among the 19 asthenopia cases, 16 patients were relieved from headache complaints and asthenopia after corrective lenses at 1 month follow up. After the correction of refractive errors, symptomatic relief was seen more in patients with asthenopia (80\%) than with patients without asthenopia (Table 2).

Table 1: Study subjects and diagnosis

\begin{tabular}{|l|c|}
\hline $\begin{array}{l}\text { Proportion of } \\
\text { Refractive Errors } \\
{[\mathbf{N}=\mathbf{1 0 3}]}\end{array}$ & $\begin{array}{c}\text { Proportion of Asthenopia in } \\
\text { Refractive Errors [N=29] }\end{array}$ \\
\hline $\begin{array}{l}\text { Male }=53(51 \%) \\
\text { Female }=50(49 \%) \\
\text { Total RE }=29(28 \%)\end{array}$ & RE with asthenopia $=18(62 \%)$ \\
RE without asthenopia = 11(38\%) \\
\hline
\end{tabular}

103 cases with primary complaint of headache were diagnosed for RE. Abbreviations: RE (Refractive Error)

Table 2: Symptomatic relief after glass prescription

\begin{tabular}{|l|c|c|}
\hline Type of refractive error & $\begin{array}{c}\text { Patients } \\
(\mathbf{n = 2 9 )} \mathbf{( 1 0 0 \% )}\end{array}$ & $\begin{array}{c}\text { Symptoms relief } \\
(\mathbf{n = 2 0}) \mathbf{6 9 \%})\end{array}$ \\
\hline Myopia & $6(20.69 \%)$ & $1(16 \%)$ \\
\hline Hypermetropia & $9(31.03 \%)$ & $8(89 \%)$ \\
\hline Simple Myopic Astigmatism & $2(6.90 \%)$ & $2(100 \%)$ \\
\hline Compound Myopic Astigmatism & $4(13.79 \%)$ & $2(50 \%)$ \\
\hline Compound Hypermetropic Astigmatism & $3(10.34 \%)$ & $3(100 \%)$ \\
\hline Mixed Astigmatism & $5(17.24 \%)$ & $4(80 \%)$ \\
\hline
\end{tabular}

Symptoms relief was seen more in simple myopic astigmatism and compound hypermetropic astigmatism followed by hypermetropia. 


\section{Discussion}

It has been believed that uncorrected refractive errors may cause eyestrain and headache irrespective of age and sex. This hypothesis is under controversy for a long period of time with researches done in different populations with contradictory conclusions. ${ }^{11-13}$ Several studies have been conducted to find out the relationship between headache and refractive error. Even though the International Headache society (IHS) categorized 'headache associated with refractive error' under secondary headaches, the IHS did not cite any evidence in support of its classification. ${ }^{14}$

By analyzing the rate of RE distribution among headache cases, we have observed $28.15 \%$ of REs from the 103 patients involved. This rate is similar in trends with most of the studies conducted in different time periods. Gordon et al 1966 examined 100 patients with headache and found that $28 \%$ had headache associated REs. ${ }^{14}$ By comparing the headache group and normal population, Akinci et al 2008, found a significant association of REs $(34.2 \%)$ with the headache group. ${ }^{15}$ There are also fewer studies that declare no significant difference in the distribution of RE between headache group and the normal population. ${ }^{16,13}$

Among the type of REs distributed over headache, hypermetropia is the most common refractive error diagnosed. Myopia, mixed astigmatism, compound myopic astigmatism, compound hypermetropic astigmatism, simple myopic astigmatism are the next common refractive error in the order of decreasing frequency.

Hypermetropia and astigmatisms are found to be the recurring REs among headache. ${ }^{17}$ Akinci et al found that hypermetropia and myopia were distributed equally among the headache group and normal population whereas astigmatism is found more common only in the headache group. ${ }^{15}$ In hypermetropia and astigmatisms, the mechanism behind headache is not well explained but it may be due to blur eye and strain. ${ }^{12}$ Astigmatic correction of $0.25 \mathrm{D}$ could be sufficient to produce relief of many headache complaints. ${ }^{18}$ Gil-Gouveia et al 2002, found that hypermetropia appears to be more linked with patients suffering from chronic headache. ${ }^{1}$ Eckhardt et al 1943, found that simulated hypermetropia and astigmatism leads to ocular discomfort after a short period of time and simulated myopia did not lead to ocular discomfort. But the experimental method is not described in this study. ${ }^{19}$

After spectacle correction, symptom relief was seen in patients with hypermetropia and astigmatism. In simple myopic astigmatism and compound hypermetropic astigmatism, $100 \%$ relief was observed. Among hypermetropia, $89 \%$ of cases experienced relief after RE correction which is least effective in myopia (16\%) during the follow up. Overall headache relief after RE correction of the present study is $69 \%$ in one month which positively correlates the importance of RE determination and correction in headache management.
The headache recovery rate of the study is compatible with the previously published data. Turville et al in 1934 analyzed the relation of REs with headache in 123 patients and found $60 \%$ of REs were hypermetropia of which $80 \%$ symptom relief was seen after spectacle correction. ${ }^{11}$ Roth et al 2008, states that improvement in headache relief is irrespective of RE correction in school children. ${ }^{13}$ In the same year, Dotan et al 2014, found that $87.5 \%$ of children diagnosed with REs experienced complete resolution from headache after RE correction in 1 month to 3years follow up. ${ }^{12}$

Headache is a characteristic of asthenopia accompanied with ocular discomfort, heaviness of eyelids, and brow acheetc. Astheniopia is caused by prolonged near work and strain in accommodation convergence system. ${ }^{20}$ By correcting the RE associated with asthenopia, headache and its associated symptoms will be relieved. In our study asthenopia were more common in patients with hypermetropia and astigmatism. Significant improvement was observed $(80 \%)$ in patients with asthenopia after RE correction.

\section{Conclusion}

A significant number of people suffering from headache comes under the category of headache attributed to RE (HARE)' and the same should be taken into the consideration of ophthalmologist. The beneficiary effect of RE measurement in headache is the symptomatic relief achieved in majority of the cases after RE correction. Despite of the controversies posing the relationship of REs and headache, the results of our study supports the fact that, 'symptomatic relief is obtained from headache in patients suffering from HARE after RE correction'. Even when the pathogenesis of HARE is not clear, the high recovery rate of hypermetropia and astigmatisms and poor outcome in myopia of the present study states that painful contracture of the ciliary muscle in sustained focusing of near objects could be the reason. A small proportion of people in which symptoms aren't relieved after RE correction, the headache could be related to eye in such a way through ocular diseases and neuroophthalmic conditions. We conclude that visual defects could be a risk factor or stimulating factor for headache and ophthalmologic referral is highly recommended.

\section{References}

1. Gil-Gouveia R, Martins IP. Headaches associated with refractive errors: myth or reality? Headache. 2002 Apr;42(4):256-62.

2. Hendricks TJ, De Brabander J, Van Der Horst Fg, Hendrikse F, KnottnerusJa. Relationship between Habitual Refractive Errors and Headache complaints In Schoolchildren. Optom Vis Sci. 2007;84:135-43.

3. Lipton RB, Hamelsky SW, Stewart WF. Epidemiology and Impact of Headache. In: Silberstein SD, Lipton RB, Dalessio DJ, Eds. Wolff's Headache And Other Head Pain, $7^{\text {th }}$ Ed. Oxford: Oxford University Press; 2001:p85107. 
4. Headache Classification committee of the International Headache society. The International Classification of Headache Disorders, $3^{\text {rd }}$ Edition (Beta Version). Cephalgia. 2013;33:629-808.

5. Rima M, Dafer, Walter M. Headache and the Eye. Curr $O$ Pin Ophthalmol. 2009; 24:22-8.

6. Freidman DI. Headache and the Eye. Current Pain and Headache Reports. 2008;12:296-304.

7. Waters WE. Headache and the eye. A community study. Lancet. 1970 Jul 4;2(7662):1-4.

8. Cameron ME. Headaches in relation to the eyes. Med $J$ Aust. 1976 Mar 6;1(10):292-4.

9. Abrams D, Duke-Elder S. Duke-Elder's Practice of Refraction. $10^{\text {th }}$ Ed. London: Churchill Livingstone; 1993.P.57-63.

10. Simons K. Hyperopia, accommodative dysfunction and reading. Binocul Vis Strabismus Q. 2004;19(2):69-70.

11. Turville, AE. Refraction and Migraine. Br. J. Physiol. Opt. 1934;10:62 -80.

12. Dotan G, Stolovitch C, Moisseiev E, Cohen S, Kesler A. Uncorrected amteropia among children hospitalized for headache evaluation: a clinical descriptive study. $B M C$ Pediatrics. 2014 Sep 29;14:241.

13. Roth Z, Pandolfo KR, Simon J, Zobal-Ratner J. Headache and Refractive Errors in Children. J Pediatr Ophthalmol Strabismus. 2014 May 6;51(3):177-9.

14. Gordon DM. Some Headaches in An Ophthalmologists Office. Headache.1966;6:140-45.

15. Akinci A, Guven A, Degerliyurt A, Kibar E, Mutlu M, Citirik M. The correlation between headache and refractive errors. J AAPOS. 2008 Jun;12(3):290-3.

16. Abolbashari F, Hosseini SMA, AliYekta A, Khabazkhoob M. The Correlation between Refractive Errors and Headache in the Young Adults. Austin J ClinOphthalmol. 2014;1(3):1014.

17. Prabhu PB, N F, Raju KV. Role of Refractive Errors in Inducing Asthenopic Symptoms Among Spectacle Corrected Ammetropes. BMH Medical Journal - ISSN 2348-392X. 2016 Jan 25;3(2):32-6.

18. Snell S. Eyestrain AS A Cause of Headache and Other Neuroses. Simpkin, Marshall, Hamilton, Kent and Co. London. 1904;16:1-6.

19. Eckhardt LB, Mclean JM, Goodell H. Experimental Studies on Headache: The Genesis of pain from the Eye. Ophthalmol. 1943;2:209-27.

20. Lanche RK. Asthenopia caused by "against the rule" astigmatism. Headache 1966;6:146-50. 